\title{
Goat pasteurellosis: serological analysis of circulating Pasteurella serotypes in Tanqua Aberegelle and Kola Tembien Districts, Northern Ethiopia
}

\author{
Guash Abay Assefa ${ }^{*^{*}}$ (10 and Mulalem Zenebe Kelkay ${ }^{2}$
}

\begin{abstract}
Objectives: A cross-sectional study was employed with the aim to explore the serological status of goats; we evaluated the presence of serum antibodies of the circulating serotypes of the genus Pasteurella. A total of 124 serum samples were collected from randomly selected goats and subsequently serotyped using indirect haemagglutination test.

Results: In the current study, the overall prevalence of pasteurellosis in goats was $31.4 \%$. Additionally, a total of eight serotypes of Pasteurella were serotyped. It is evident that $25 \%$ out of 124 sampled animals were found infected by four or more circulating serotypes and $6.4 \%$ animals were also found positive for all serotypes. Accordingly, the prevalence of Pasteurella multocida serotype A were 16.9\%, Mannheimia haemolytica serotype A1 26.6\%, M. haemolytica serotype A2 18.5\%, M. haemolytica serotype A7 16.1\%, Bibersteinia trehalosi serotype T3 20.9\%, B. trehalosi serotype T4 21.7\%, B. trehalosi serotype $\mathrm{T} 1027.4 \%$, and B. trehalosi serotype $\mathrm{T} 15$ was $25.8 \%$. Therefore, although there has been vaccination campaign with monovalent vaccine P. multocida type A, the diseases still exerts negative impacts through death of goats to smallholder farmers. Therefore, to control the disease the government should provide multivalent vaccine of the above serotypes.
\end{abstract}

Keywords: Goat, Kola Tembien, Pasteurella, Serotyping, Tanqua Abergelle

\section{Introduction}

In Ethiopia, goat pasteurellosis caused by Pasteurella is more prevalent and where outbreak occur lead to high mortality. Pasteurella multocida or Mannheimia haemolytica are the main causes for respiratory pasteurellosis in sheep and goats of all age groups [1]. It can be particularly devastating in young animals. It is a common cause of high morbidity and mortality in kids, especially in those that have not received adequate colostrum. The disease appears to occur most often in animals that have undergone recent stress such as transportation, weaning, or commingling with animals from unrelated farms [2].

\footnotetext{
*Correspondence: guashaba81@gmail.com

${ }^{1}$ Abergelle Agricultural Research Center, P.O. Box 44, Abi Adi, Ethiopia

Full list of author information is available at the end of the article
}

Development of carrier status or latent infections plays a critical role in the epidemiology of the diseases [3].

Even though there had been research works done on animal health in Tigray region, there is no evidence that shows the clear picture of the serotypes causing pasteurellosis in the study districts. Based on the information obtained from the districts veterinary services large and small ruminant pasteurellosis is one of the major health problems and the vaccination is done by purchasing the recommended vaccine from the National Veterinary Institute (NVI) which is developed from only P. multocida type A, resulting poor vaccine efficacy. Although there is a vaccination campaign once each year, vaccination is irregular because of inadequate vaccine supply and lack of farmer awareness. Hence, this research study was conducted to know the existing serotypes from randomly selected goats. 


\section{Main text}

\section{Materials and methods}

Study area

As shown in Fig. 1, the study was conducted in Kola Tembien, and Tanqua Abergelle districts for disease investigation and sample collection. The study districts are categorized as hot to warm sub-moist low lands sub-agro ecological zone of the region with an altitude of 1300-1500 $\mathrm{m}$ above sea level and the mean annual rainfall ranging from 400 to $600 \mathrm{~mm}$, which is characterized by low, erratic and variable rainfall. The annual temperature ranges from 28 to $42{ }^{\circ} \mathrm{C}$ [4].

\section{Study methodology}

In the current study, a cross sectional study design was used to identify the circulating serotypes of Pasteurella. Individual animals were selected randomly with no prior vaccination against the disease in both study districts regardless of their age and sex. Blood samples $(5 \mathrm{ml})$ were withdrawn aseptically from the external jugular vein using plain vacutainer tubes. For this purpose, a total of 124 blood samples were collected and subsequently allowed to clot, and then serum was separated immediately by centrifugation at $1500 \mathrm{~g}$ for $10 \mathrm{~min}$. Serum samples were stored in refrigerator at a temperature of $-20{ }^{\circ} \mathrm{C}$ and were taken to NVI for serological identification using IHAT. Each serum samples were serotyped using the reference serotypes available in NVI using IHAT. The objective of indirect haemagglutination test is to detect the presence of antibody of Pasteurella and Manhaemia in the serum sample. The IHAT antibody titres of all the samples were recorded in comparison with the positive and negative controls. Positive results were taken if the level of antibody titer was greater than 1:10 (Additional file 1).

\section{Sample size determination}

The sample size for the study was determined according to the formula given by [5] for the purpose of random sampling method. A 5\% absolute precision and 95\% confidence interval was used to determine the sample size. An expected prevalence of $8.46 \%$ was taken to determine the maximum sample size [6]. Accordingly, 119 animals were used for the present study.

$$
N=\frac{1.96^{2} P_{\exp }\left(1-P_{\exp }\right)}{d^{2}}
$$

where $\mathrm{n}$ is total sample size; $\mathrm{d}$ is absolute precision; and $\mathrm{P}_{\exp }$ is expected prevalence.

\section{Data analysis}

Data were entered into Microsoft excel and analyzed using descriptive statistics so as to compare the circulating serotypes in terms of frequency.

\section{Result}

\section{Prevalence of Pasteurella and Manhaemia serotypes}

Infection in goat due to Pasteurella species is the main contributor for economical loss in the study districts. The prevalence of pasteurellosis serotypes in the study districts is given in Table 1.

Out of the 124 goats sampled, the prevalence of seropositive goats was $16.9 \%(21 / 124)$ for $P$. multocida, $28.2 \%$ (35/124) for M. haemolytica, and 31.4\% (39/124) for Bibersteinia trehalosi. The overall prevalence of pasteurellosis in goat in the study districts were $31.4 \%$ (39/124). The study shown that a higher prevalence of $M$. haemolytica (28.2\%) and B. trehalosi (31.4\%).

Of the 124 tested animals 31 (25\%) animals were infected by four or more serotypes. Additionally, 8 (6.45\%) animals, 7 (5.6\%) animals, 8 (6.45\%) animals, 4 (3.2\%) animals, 5 (4.0\%) animals were infected by eight, seven, six, five, and four serotypes respectively.

Overall, the most prevalent serotypes identified were Pasteurella trehalosi serotype T10, M. haemolytica serotype A1, B. trehalosi serotype T15, B. trehalosi serotype T4, B. trehalosi serotype T3, and M. haemolytica serotype A2.

\section{Discussion}

Pasteurellosis is among the most important infectious diseases of goats in the study districts that causes huge economical loss through death. In these study districts, the disease is mostly associated to stress conditions such as drought, heat, and usually commence during the beginning of rain fall.

The species are commensally resident in the upper respiratory tract of healthy ruminants and are capable of causing infection when animals immunity become compromised [7].

In the present study, the dominant pasteurella species encountered were B. trehalosi (31.4\%), and M. haemolytica (28.2\%). Therefore, these pasteurella species are the dominant causative agents for pasteurellosis infection in the study districts. The results published here are in agreement with those of other authors [8-10]. In contrast to our study $M$. haemolytica in goat was not dominant in different studies [11]. Our finding shows higher prevalence (31.4\%) in pasteurellosis infection. [10] Have found a prevalence of $21.9 \%$ which is below to our study. In the current study the prevalence is higher as compared to previous report $(8.46 \%)$ by [6] in the same study districts. This high prevalence in our study may be due to high 


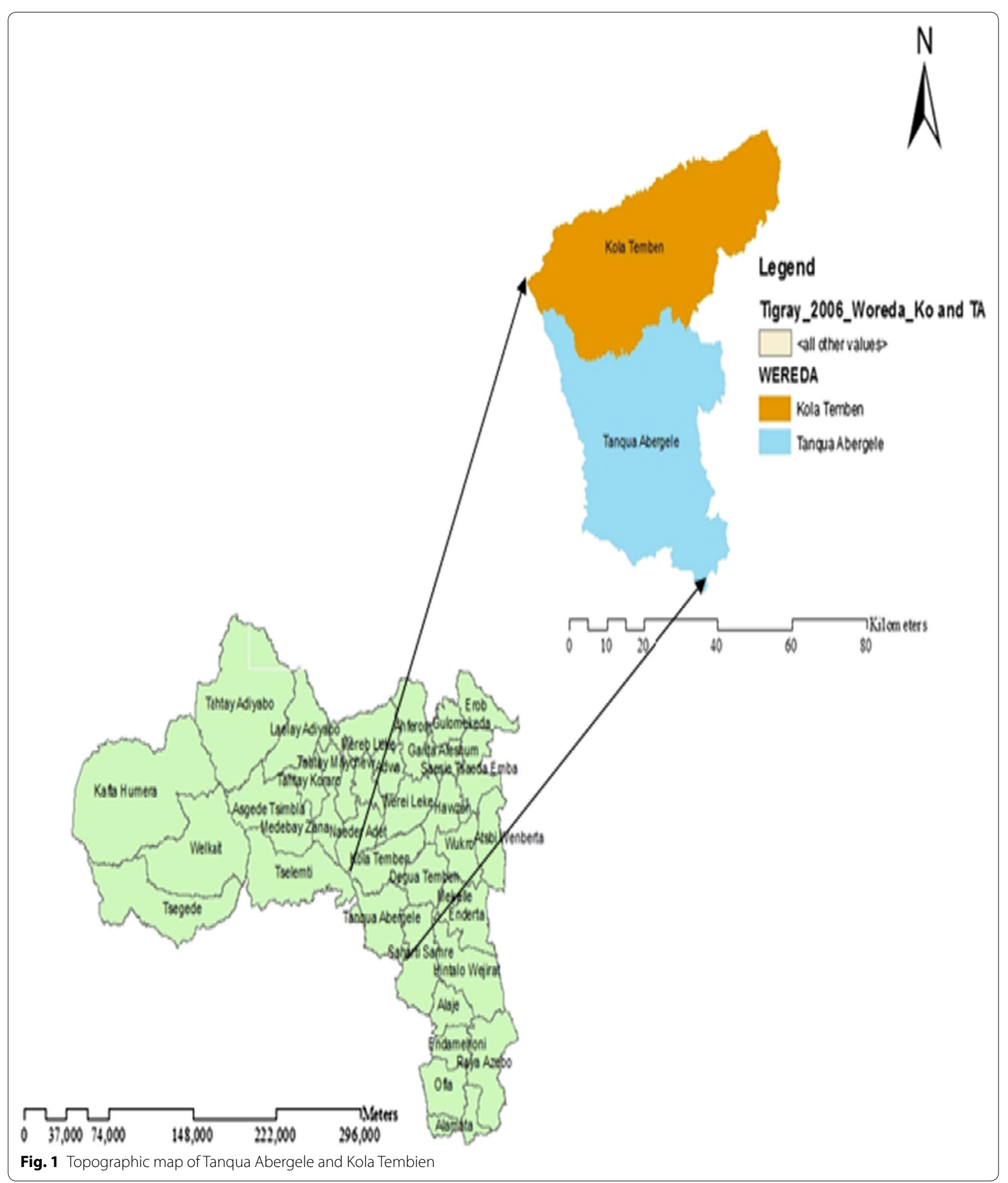


Table 1 Prevalence of Pasteurella serotypes in the study districts

\begin{tabular}{lll}
\hline Serotype name & Positive cases & Percent \\
\hline Pasteurella multocida serotype A & 21 & 16.9 \\
Mannheimia haemolytica serotype A1 & 33 & 26.6 \\
Mannheimia haemolytica serotype A2 & 23 & 18.5 \\
Mannheimia haemolytica serotype A7 & 20 & 16.1 \\
Bibersteinia trehalosi serotype T3 & 26 & 20.9 \\
Bibersteinia trehalosi serotype T4 & 27 & 21.7 \\
Bibersteinia trehalosi serotype T10 & 34 & 27.4 \\
Bibersteinia trehalosi serotype T15 & 32 & 25.8 \\
\hline
\end{tabular}

environmental stress factors (heat, drought, feed and water shortages) in the study districts since 2015. Transportation, viral infections, drought, overcrowding, housing of neonates and weaned animals together and other stressful conditions predispose animals to $M$. haemolytica and P. multocida infection [12, 13]. M. haemolytica serotype A1 in the study district were isolated with the prevalence of $26.6 \%$ which is higher than the findings of [14] which they found with the prevalence of $19 \%$ in Bishoftu district.

In our findings, a combination of more than two serotypes infection on a single animal has been observed. Similar to our findings, [15] has been showed mixed infection of serotypes on a single animal in Tigray region districts.

\section{Conclusions}

In conclusion, higher prevalence of pasteurellosis infection was found in the study districts. About eight serotypes of Pasteurella species were serotyped. Therefore, multivalent Pasteurella vaccine or a single vaccine of the identified serotypes should be developed and regular vaccination with full area coverage should be practiced.

\section{Limitations}

This research was only conducted to know the serotypes of Pasteurella by using IHAT. Further isolation and characterization of the serotypes has not been conducted.

\section{Additional file}

Additional file 1. The data collected (serum) for this study.

\section{Abbreviations}

IHAT: indirect haemagglutination test; NVI: National Veterinary Institute; ml: milliliter; ${ }^{\circ} \mathrm{C}$ : degree centigrade.
Authors' contributions

GA conducted laboratory analysis, data analysis, full write up, processing the paper for publication. MZ designed the study design, and has collected data. Both authors read and approved the final manuscript.

\section{Author details}

${ }^{1}$ Abergelle Agricultural Research Center, P.O. Box 44, Abi Adi, Ethiopia. ${ }^{2}$ ShireMaytsebri Agricultural Research Center, P.O. Box 81, Shire, Ethiopia.

\section{Acknowledgements}

The authors would like to thank to Dr. Zelealem Tesfay and Dr. Teshale Teklu for their constructive comment and to the farmers for their cooperation during data collection.

\section{Competing interests}

The authors declare that they have no competing interests.

\section{Availability of data and materials}

All data are deposited or submitted as additional file.

Consent for publication

Not applicable.

\section{Ethics approval and consent to participate}

Ethical approval was exempted by Mekelle University College of Veterinary Medicine Research and Community service office. We did a verbal communication with the farmers and I have got an informed consent from the farmers to collect a blood sample.

\section{Funding}

The authors would like to thank to Tigray Agricultural Research Institute who support for financial assistance.

\section{Publisher's Note}

Springer Nature remains neutral with regard to jurisdictional claims in published maps and institutional affiliations.

Received: 11 June 2018 Accepted: 13 July 2018

Published online: 17 July 2018

\section{References}

1. Deressa A, Asfaw Y, Lubke B, Kyule M, Tefera G, Zessin KH. Molecular Detection of Pasteurella multocida and Mannheimia haemolytica in Sheep Respiratory Infections in Ethiopia. Int J Appl Res Vet Med. 2010;8(2):101.

2. Kahn CM. The Merck veterinary manual. 9th ed. Amsterdam: Elsevier health science; 2010.

3. Dziva F, Muhairwa AP, Bisgaard M, Christensen H. Diagnostic and typing options for investigating diseases associated with Pasteurella multocida: review. Vet Microbiol. 2008;128:1-22.

4. Bureau of agricultural and rural development of Woreda Tanqua Abergelle and Woreda Kola Tembien; 2015.

5. Thrusfield M. Sampling in veterinary epidemiology. 2nd ed. London: Blackwell Science; 2008

6. Guash A, Mulalem Z, Daniel D, Hailai H, Minister B, Tsegay T. Clinical survey on major ruminant diseases in Kola Tembien and Tanqua Abergelle districts, Central zone of Tigray region, Northern Ethiopia. J Vet Med Anim Health. 2017;9(12):342-8.

7. Radostits OM, Gay CC, Hinchcliff KW, Constable PD, editors. Veterinary medicine e-book: a textbook of the diseases of cattle, horses, sheep, pigs and goats. Amsterdam: Elsevier Health Sciences; 2006.

8. Villard L, Gauthier D, Lacheretz A, Abadie G, Game Y, Maurin F, Richard Y, Borges E, Kodjo A. Serological and molecular comparison of Mannheimia haemolytica and Bibersteinia trehalosi strains isolated from wild and domestic ruminants in the French Alps. Vet J. 2006;171:545-50.

9. Haimanot D, Marru T, Anijajo T, Hassen AA. A study on ovine puemonic pasteurellosis: isolation and identification of Pasteurella and their 
antibiogram susceptibility pattern in Haramaya district, Eastern Hararghe, Ethiopia. BMC Vet Res. 2013;9:239.

10. Tewodros AA, Annania TA. Pasteurellosis in small ruminants: biochemical isolation, characterization and prevalence determination in relation to associated risk factors in Fogera Woreda, North-West Ethiopia. Adv Biol Res. 2015;9(5):330-7.

11. Hussien K, EL-Dahshan AR, Zaki MM, Shimaa A. Occurrence of Mannheimia haemolytica and Bibersteinia trehalosi among Ruminants in Egypt. N Y Sci J. 2010;3(5):135-41.

12. Frank GH, Briggs RE, Loan RW, Purdy CW, Zehr ES. Respiratory tract disease and mucosal colonization by Pasteurella haemolytica in transported cattle. Am J Vet Res. 1996;57:1317-20.
13. Brogden KA, Lehmkuhl HD, Cutlip RC. Pasteurella haemolytica complicated respiratory infections in sheep and goats. Vet Res. 1998;29:233-54.

14. Demissie T, Dawo F, Sisay T. Biochemical and antigenic characterization of Mannheimia, pasteurella and Mycoplasma species from naturally infected pneumonic sheep and goats, Bishoftu, Ethiopia. Afr J Basic Appl Sci. 2014;6(6):198-204.

15. Berhe K, Weldeselassie G, Bettridge J, Christley RM, Abdi RD. Small ruminant pasteurellosis in Tigray region, Ethiopia: marked serotype diversity may affect vaccine efficacy. Epidemiol Infect. 2017;145:1-13.
Ready to submit your research? Choose BMC and benefit from:

- fast, convenient online submission

- thorough peer review by experienced researchers in your field

- rapid publication on acceptance

- support for research data, including large and complex data types

- gold Open Access which fosters wider collaboration and increased citations

- maximum visibility for your research: over 100M website views per year

At BMC, research is always in progress.

Learn more biomedcentral.com/submissions 